\title{
Pelatihan Penulisan Penelitian Tindakan Kelas pada Guru di Lingkungan Muhammadiyah Boarding School Ki Bagus Hadikusumo
}

\author{
Training on Writing Classroom Action Research for Teachers at the Ki Bagus Hadikusumo \\ Muhammadiyah Boarding School
}

M Koesmawan
Elliya Sestri
Isnan Hari Mardika*
Department of Management, Institut
Teknologi dan Bisnis Ahmad Dahlan,
Jakarta, DKI Jakarta, Indonesia
*email: isnandicka@gmail.com
Kata Kunci
Penelitian Tindakan Kelas
Guru
Boarding School
Keywords:
Classroom Action Research
Teacher
Boarding School
Received: June 2019
Accepted: September 2019
Published: September 2019

\begin{abstract}
Abstrak
Penulisan karya ilmiah merupakan kegiatan yang sangat penting bagi seorang Guru yang profesional. Kegiatan ini tidak saja perlu dilakukan dalam rangka memperoleh angka kredit untuk kenaikan jabatan atau untuk keperluan sertifikasi melalui portofolio, tetapi terlebih lagi perlu dilakukan dalam rangka peningkatan kualitas pengelolaan kelas, kualitas layanan kepada anak didik, dan juga peningkatan profesionalisme Guru itu sendiri. Hasil pelaksanaan kegiatan pengabdian secara keseluruhan dapat dilihat berdasarkan beberapa komponen berikut ini. Pertama, Target peserta pelatihan atau khalayak sasaran adalah 36 Muhammadiyah Boarding School (MBS) Ki Bagus Hadikusumo. Dalam pelaksanaannya kegiatan ini diikuti oleh 22 orang guru karena ada beberapa guru yang mempunyai kegiatan di luar sekolah. Dengan demikian ketercapaian target jumlah peserta pelatihan adalah $61,1 \%$ atau dapat dinilai cukup baik. Kedua, Ketercapaian tujuan pelatihan dapat dinilai kurang baik. Dalam kurun waktu dua minggu sebanyak 9 orang guru $(40,9 \%)$ telah berusaha menyusun proposal.
\end{abstract}

\begin{abstract}
Writing scientific papers is a very important activity for a professional teacher. This activity not only needs to be done in order to obtain credit figures for promotion or for the purposes of certification through portfolios, but moreover, it needs to be done in order to improve the quality of classroom management, quality of service to students, and also increase the professionalism of the teacher himself. The results of the overall community service activity can be seen based on the following components. First, the target of the training participants or target audience is 36 Muhammadiyah Boarding Schools (MBS) Ki Bagus Hadikusumo. In the implementation of this activity, it was attended by 22 teachers because there were several teachers who had activities outside of school. Thus the target number of training participants is $61.1 \%$ or can be considered quite good. Secondly, the achievement of training objectives can be judged to be poor. Within a period of two weeks as many as 9 teachers $(40.9 \%)$ had tried to prepare a proposal.
\end{abstract} (http://creativecommons.org/licenses/by-sa/4.0/). DOI: https://doi.org/10.33084/ pengabdianmu.v4i2.843.

\section{PENDAHULUAN}

Penulisan karya ilmiah merupakan kegiatan yang sangat penting bagi seorang Guru yang profesional. Kegiatan ini tidak hanya perlu dilaksanakan dalam rangka memperoleh angka kredit guna untuk kenaikan jabatan atau untuk keperluan sertifikasi guru melalui portofolio, tetapi terlebih lagi perlu dilaksanakan lebih bertujuan untuk peningkatan kualitas pengelolaan kelas, kualitas layanan pembelajaran kepada anak didik, dan juga untuk meningkatkan profesionalisme Guru itu sendiri (Gunawan et al., 2018; Susantini etal., 2015). Artikel ilmiah 
yang berisi hasil penelitian, hasil pelatihan, hasil pemikiran, pendampingan dan karya Guru lainnya, sangat potensial sebagai wahana komunikasi dan diseminasi karya dan ide kepada Guru atau orang lain (Arta, 2018; Dwijayanti et al., 2017; Jaedun, 2009).

Guru yang profesional tidak hanya melakukan fungsi terkait dengan kompetensi pedagogis (khususnya merencana, melakukan, menilai dan mengadministrasi pembelajaran), tetapi juga fungsi yang terkait dengan kompetensi kepribadian, sosial, serta keprofesionalan, yang antara lain ditandai dengan peningkatan diri melalui menulis karya ilmiah. Oleh karena itu, setiap Guru sudah seharusnya mau, mampu, dan biasa melakukan kegiatan penelitian kegiatan kelas kemudian membuat karya ilmiah (Novauli, 2015; Jaedun, 2009).

Kenyataanya, di lapangan banyak guru yang belum mau, mampu, dan biasa melakukan kegiatan penulisan karya ilmiah. Dari ribuan Guru yang ada, hanya beberapa puluh saja yang bisa menunjukkan bahwa mereka memiliki kemampuan, kemauan, dan kebiasaan menulis ini. Hal ini ditandai dengan kemampuan mereka mencapai tingkat golongan $\mathrm{IVb}$ dan kemunculan beberapa tulisanya pada sebuah koran, majalah atau terbitan lainnya. Sebagian besar Guru masih memiliki kendala seperti merasa berat dan sulit untuk menulis atau menuangkan ide mereka menjadi tulisan (Pambudi, 2018; Noorjannah, 2014).

Beberapa hasil pengamatan dan wawancara kepada para Guru, banyak memberikan kejelasan mengapa Guru belum mampu, mau, dan biasa menulis ilmiah (Ayudia et al., 2016; Jaedun, 2009). Dua aspek atau faktor dari sekian faktor yang muncul dari pengamatan dan wawancara ini adalah motivasi dan substansi. Aspek motivasi, terkait dengan belum munculnya minat, semangat, dan keinginan kuat dari para Guru untuk memulai menulis karya ilmiah. Bahkan secara tegas, sebagian besar Guru menyatakan puas sampai pada golongan IVa saja, manakala untuk naik ke IVb harus menulis karya ilmiah. Beberapa alasan penyebab rendahnya motivasi menulis karya ilmiah ini adalah ketakutan dan atau kecemasan menulis terkait dengan prosedur dan kriteria tulisan yang dapat diterima dan dihargai sebagai karya ilmiah (Anggraini, 2011; Jaedun, 2009).

Sebagian terbesar mereka menyatakan bahwa prosedur pembuatan karya ilmiah dan kriteria itu terlalu sulit untuk mereka penuhi atau ikuti. Sementara aspek substansi, terkait dengan isi atau bahan tulisan. Sebagian besar dari Guru yang belum mau, mampu, dan biasa menulis, lebih disebabkan belum atau tidak adanya bahan yang layak untuk ditulis. Mereka menyatakan belum mempunyai waktu untuk melakukan penelitian, dan mencari sumber-sumber bacaan untuk ditulis (Yulhendri et al., 2018; Jaedun, 2009).

Berdasarkan pada pengalaman penelitian ini penulis mengertahui bahwa cara yang paling mudah untuk menulis artikel ilmiah adalah menulis dari hasil penelitian. Dari sekian jenis penelitian, Penelitian Tindakan Kelas (PTK) merupakan jenis penelitian yang paling memungkinkan dan sangat tepat bagi Guru. PTK bahkan merupakan program khusus dari program pemerintah dalam upaya peningkatan kualitas Guru dan tenaga kependidikan pada umumnya (Afandi, 2014; Jaedun, 2009). Portofolio untuk sertifikasi dan angka kredit kenaikan pangkat Guru, secara khusus juga memberikan ruang bagi pemuatan hasil PTK Guru. Kemudian, dalam hal ini Pemerintah juga secara khusus setiap tahun menganggarkan untuk memberikan dana bagi Guru yang mampu membuat dan melakukan PTK dengan baik (Noorjannah, 2014).

Posisi PTK menjadi semakin strategis bahkan mendapatkan tempat khusus sebagai prioritas untuk bisa dilakukan Guru, mengingat adanya manfaat ganda dari PTK (Afandi, 2014). Pertama, pelaksanaan kegiatan 
PTK yang terencana dan terkelola secara baik, akan mampu meningkatkan kinerja Guru dalam mengelola pembelajaran dikelas dengan lebih berkualitas. Dengan kata lain, pelaksanaan kegiatan PTK akan berdampak pada peningkatan kompetensi Guru, yang pada saat ini sedang menjadi isu utama dalam upaya peningkatan mutu pendidikan nasional. Kedua, dalam menyelesaikan masalah - masalah yang ada didalam kelas atau pembelajaran akan dapat memberikan pengalaman kepada guru sehingga guru dapat melakukan perbaikan - perbaikan pada kualitas proses pembelajaran. Ketiga, perbaikan peran Guru dalam pembelajaran baik secara kompetensi maupun pengalaman, akan meningkatkan kualitas belajar pada siswa, yang pada saatnya akan dapat mengangkat prestasi atau hasil belajar siswa, dan perbaikan hasil belajar siswa, secara akumulatif, akan mampu memberikan kontribusi bagi peningkatan kualitas pendidikan secara nasional (Arikunto et al., 2006). Tujuan kegiatan Pengabdian ini adalah agar para guru dapat meningkatkan wawasn tentang PTK, selain juga untuk meningkatkan kompetensi professional guru melalui implementasi PTK, serta agar para guru dapat menulis laporan PTK dengan baik. Khalayak sasaran kegiatan pengabdian adalah guru-guru dilingkungan Muhammadiyah Boarding School (MBS) Ki Bagus Hadikusumo, Jampang, Bogor. Manfaat yang diharapkan dari kegiatan pengabdian adalah yang pertama Guru dapat meningkatkan wawasannya tentang PTK. Kedua, Guru dapat meningkatkan kompetensi profesional melalui implementasi PTK dan terakhir adalah guru - guru dapat menulis laporan PTK.

\section{METODOLOGI}

Khalayak sasaran kegiatan pengabdian adalah guruguru dilingkungan MBS Ki Bagus Hadikusumo, Jampang, Bogor. Berdasarkan informasi dari Mudir MBS
Ki Bagus Hadikusumo, maka jumlah khalayak sasaran dalam kegiatan pengabdian berjumlah 36 orang guru. Kegiatan ini dilaksanakan dengan beberapa tahap. Tahap pertama adalah melakukan analisis awal kondisi guru-guru pada MBS Ki Bagus Hadikusumo yang dilaksanakan pada hari sabtu 5 januari 2019 dengan mendapatkan hasil data awal pengetahuan masing masing guru MBS Ki Bagus Hadikusumo. Kemudian pada tanggal 12 Januari 2019 dilaksanakan kegiatan pelatihan penulisan Penelitian Tindakan Kelas bagi guru MBS Ki Bagus Hadikusumo.

Metode kegiatan yang digunakan dalam kegiatan pelatihan yaitu, pertama ceramah, ceramah digunakan oleh tim pengabdi untuk menyampaikan prinsip-prinsip PTK, prosedur PTK, implementasi PTK, dan prosedur penulisan laporan PTK (Setianingsih et al., 2015; Hendikawati et al., 2016). Ceramah didukung pemanfaatan laptop dan LCD untuk menayangkan materi pengabdian dalam waktu terbatas. Kedua, Demonstrasi digunakan oleh tim pengabdi dengan harapan peserta dapat mulai mempraktekkan penyusunan masalah dalam proses pembelajaran yang dapat dipecahkan melalui PTK, rancangan proposal PTK, hingga penulisan laporan PTK. Untuk mengoptimalkan pelaksanaan pengabdian dilakukan pendampingan oleh tim pengabdi, yaitu dalam penyusunan rancangan proposal PTK dan penulisan laporan PTK (Hendikawati et al., 2016), Matriks tujuan hingga hasil analisis luaran disajikan pada Tabel I.

Tabel I. Matriks Tujuan, Jenis Data, Teknik Analisis dan Keluaran Hasil Analisis

\begin{tabular}{|c|c|c|}
\hline Tujuan Penelitian & $\begin{array}{c}\text { Metode \& } \\
\text { Teknik Analisis }\end{array}$ & $\begin{array}{c}\text { Keluaran } \\
\text { (Output) }\end{array}$ \\
\hline $\begin{array}{l}\text { 1. Meningkatkan } \\
\text { pemahaman guru- } \\
\text { guru MBS Ki Bagus } \\
\text { Hadikusumo tentang } \\
\text { PTK }\end{array}$ & $\begin{array}{l}\text { 1.Ceramah } \\
\text { 2.Demonstrasi }\end{array}$ & $\begin{array}{l}\text { Karya } \\
\text { Ilmiah } \\
\text { Guru }\end{array}$ \\
\hline $\begin{array}{l}\text { 2. Meningkatkan } \\
\text { kemampuan guru } \\
\text { dalam penulisan } \\
\text { laporan PTK. }\end{array}$ & & \\
\hline
\end{tabular}




\section{HASIL DAN PEMBAHASAN}

Agenda kegiatan pengabdian di MBS Ki Bagus Kusumo dilakukan pemaparan materi dengan nara sumber adalah tim pengabdi yang berjumlah 3 (tiga) orang. Penyampaian materi dari tim pengabdi, antara lain: materi PTK (prinsip, prosedur, dan implementasi) dan materi penulisan laporan PTK. Penyampaian materi kemudian dilanjutkan dengan sesi tanya jawab mengenai berbagai kendala yang dihadapi guru dalam PTK termasuk dalam penulisan laporannya. Kegiatan pengabdian kemudian diikuti dengan praktik berupa penyusunan judul PTK, latar belakang masalah, rumusan masalah, tujuan, dan bentuk tindakan yang akan dilakukan.

Kegiatan pengabdian dilanjutkan dengan pemberian tugas individu pada para guru MBS Ki Bagus Hadikusumo untuk membuat proposal PTK atau menulis laporan PTK dalam kurun waktu dua minggu. Tugas individu bagi guru dikumpulkan secara kolektif dan diberikan kepada tim pengabdi untuk mendapatkan masukan dalam rangka perbaikan. Pendampingan dilakukan oleh tim pengabdi dengan harapan semakin banyak guru-guru MBS Ki Bagus Hadikusumo yang mengimplementasikan PTK dan sekaligus menulis laporannya. Dokumentasi kegiatan Pengabdian disajikan pada Gambar 1 dan 2.

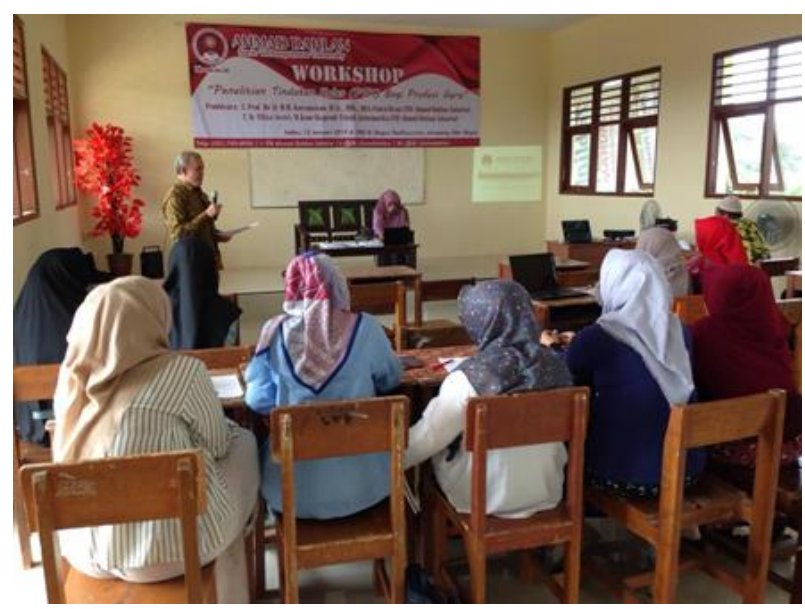

Gambar 1. penyampaian materi oleh pembicara 1

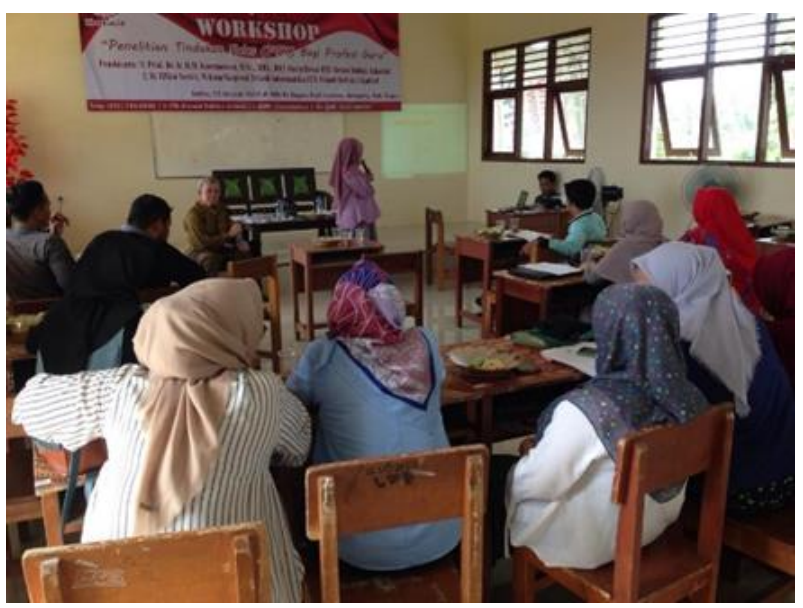

Gambar 2. penyampaian materi oleh pembicara 2

Hasil pelaksanaan kegiatan pengabdian secara keseluruhan dapat dilihat berdasarkan beberapa komponen berikut ini. Pertama, Target peserta pelatihan atau khalayak sasaran adalah 36 MBS KI Bagus Hadikusumo. Dalam pelaksanaannya kegiatan ini diikuti oleh 22 orang guru karena ada beberapa guru yang mempunyai kegiatan di luar sekolah. Dengan demikian ketercapaian target jumlah peserta pelatihan adalah $61,1 \%$ atau dapat dinilai cukup baik. Kedua, Ketercapaian tujuan pelatihan dapat dinilai kurang baik. Dalam kurun waktu 2 (dua) minggu sebanyak 9 orang guru $(40,9 \%)$ telah berusaha menyusun proposal PTK. Kendala yang dihadapi para guru dalam pengerjaan tugas individu adalah kesibukan di sekolah dan masih minimnya kemampuan menulis, oleh karena itu perlu adanya pengalakan budaya menulis. Dalam kegiatan pengabdian ini, tim pengabdi berusaha melakukan pendampingan bagi bapak/ibu guru MBS Ki Bagus Hadikusumo yang tertarik mengimplementasikan PTK dan berlatih menulis laporannya. Kedua, ketercapaian target materi yang telah direncanakan. ketercapaian target materi yang telah direncanakan pada kegiatan pengabdian ini dapat dinilai baik $(80 \%)$. Semua materi yang telah direncanakan dapat disampaikan kepada peserta, 
meskipun karena keterbatasan waktu ada beberapa materi yang hanya disampaikan secara garis besar. Hal ini diukur melalui skema pre test dan post test. Ketiga, kemampuan peserta dalam penguasaan materi, kemampuan peserta dilihat dari penguasaan materi dapat dinilai baik $(80 \%)$. Hal ini dapat dilihat dari kemampuan bapak/ibu guru dalam kegiatan praktik berupa penyusunan judul PTK, latar belakang masalah, rumusan masalah, tujuan, dan bentuk tindakan yang akan dilakukan, disamping antusiasme dalam acara tatap muka dengan memberikan beberapa pertanyaan.

\section{KESIMPULAN}

Secara keseluruhan, kegiatan pengabdian bagi guruguru MBS Ki Bagus Hadikusumo diukur dari keempat komponen di atas dapat dinilai cukup baik. Hal ini berkat dukungan banyak pihak, terutama Pimpinan MBS Ki Bagus Hadikusumo.

\section{REFERENCES}

Afandi, M. 2014. Pentingnya Penelitian Tindakan Kelas bagi Guru dalam Pembelajaran di Sekolah Dasar. Jurnal Ilmiah Pendidikan Dasar. 1(1):1-19. http://dx.doi.org/10.30659/pendas.1.1.1-19

Anggraini, I.S. 2011. Motivasi Belajar dan Faktor-Faktor yang Berpengaruh: Sebuah Kajian pada Interaksi Pembelajaran Mahasiswa. Premiere Educandum: Jurnal Pendidikan Dasar dan Pembelajaran. 1(2):100-109. http://doi.org/10.25273/pe.v1i02.39

Arikunto, S., Suhardjono, Supardi. 2006. Penelitian Tindakan Kelas. Jakarta: Bumi Aksara.

Arta, K.S. 2018. Pelatihan Penulisan Artikel Untuk Publikasi di Jurnal Ilmiah untuk Meningkatkan Profesionalisme bagi Guru Guru di Kecamatan Kubutambahan Kabupaten Buleleng. In Prosiding Seminar Nasional Hukum dan Ilmu Sosial ke-2 Merekontruksi Ilmu Hukum dan Ilmu Sosial dalam
Membangun Karakter Bangsa. Singaraja: Universitas Pendidikan Ganesha.

Ayudia, Suryanto, E., Waluyo, B. 2016. Analisis Kesalahan Penggunaan Bahasa Indonesia dalam Laporan Hasil Observasi pada Siswa SMP. Basastra: Jurnal Bahasa, Sastra, dan Pengajarannya. 4(1):34-49.

Dwijayanti, R., Marlena, N., Patrikha, F.D. 2017. Pelatihan Penulisan Karya Tulis (KTI) Bagi Guru-guru SMK di Kabupaten Jombang. Jurnal Pemberdayaan Masyarakat Madani. 1(2):249-266. https://doi.org/10.21009/JPMM.001.2.07

Gunawan, I., Triwiyanto, T., Kusumaningrum, D.E. 2018. Pendampingan Penulisan Artikel Ilmiah bagi Para Guru Sekolah Menengah Pertama. Abdimas Pedagogi: Jurnal Ilmiah Pengabdian kepada Masyarakat. 1(2):128-135.

Hendikawati, P., Rachmani, N.D.N., Susilo, B.E. 2016. Pendampingan Penyusunan Proposal Penelitian Tindakan Kelas bagi Guru MI Roudlotul Huda Gunungpati Semarang. Jurnal Abdimas. 20(1):37-42.

Jaedun, A. 2009. Peningkatan Profesionalisme Guru melalui Penelitian Tindakan Kelas. In Prosiding Seminar Nasional Meneliti Merupakan Syarat Profesional Guru. Surakarta, 3 Mei 2009.

Noorjannah, L. 2014. Pengembangan Profesionalisme Guru melalui Penulisan Karya Tulis Ilmiah bagi Guru Profesional di SMA Negeri 1 Kauman Kabupaten Tulungagung. Humanity. 10(1):97-114.

Novauli, F.M. 2015. Kompetensi Guru dalam Peningkatan Prestasi Belajar pada SMP Negeri Dalam Kota Banda Aceh. Jurnal Administrasi Pendidikan.3(1):45-67.

Pambudi, S. 2018. Upaya Meningkatkan Profesionalisme Guru Melalui Pelatihan Penelitian Tindakan Kelas di SMK Muhammadiyah 1 Bantul. Elinvo (Electronics, Informatics, and Vocational Education). 3(2):61-64. https://doi.org/10.21831/elinvo.v3i2.23460

Setianingsih, R., Manuharawati, M., Sutinah, S., Lukito, A. 2015. Pendampingan Penyusunan Proposal Penelitian Tindakan Kelas (PTK) untuk Guru Sekolah Dasar di Kecamatan Kasiman Kabupaten Bojonegoro. Jurnal Abdi: Media 
pengabdian kepada masyarakat. 1(1):61-66. http://dx.doi.org/10.26740/ja.v1n1.p61-66

Susantini, E., Rahayu, Y.S., Budiono, D., Raharjo, R. 2015. Profil Artikel Ilmiah Buatan Guru pada Pelatihan Penulisan Karya Ilmiah bagi Guru Guru di SMP LabSchool Surabaya. Jurnal Abdi : Media pengabdian kepada masyarakat. 1(1):1-7. http://dx.doi.org/10.26740/ja.v1n1.p1-7

Yulhendri, Marna, J.E., Oknaryana. 2018. Analisis Kemampuan Menulis Karya Ilmiah Guru Ekonomi di Kabupaten Pasaman Barat. JIPE (Jurnal Inovasi Pendidikan Ekonomi). 8(1):56-59. https://doi.org/10.24036/01104530 